AGRICA: Journal of Sustainable Dryland Agriculture, 14 (2): 128-136 (2021)

ISSN-Online: 2715-4955; ISSN-Cetak: 2715-6613

DOI: https://doi.org/10.37478/agr.v14i2.1531

\title{
IDENTIFIKASI TINGKAT KESUBURAN TANAH DAN SIFAT KIMIA TANAH PADA LAHAN PEMBUDIDAYAAN SAYUR-SAYURAN DI KELURAHAN REWARANGGA SELATAN
}

\author{
Abraham Banggo, Charly Mutiara*, Philipus N Supardy \\ Program studi Agroteknologi, Fakultas Pertanian Universitas Flores \\ Jln. Sam Ratulanggi XX Paupire, Ende, Nusa Tenggara Timur \\ *charlyinter1988@gmail.com
}

\begin{abstract}
Identification Of Soil Fertility Level And Soil Chemical Properties In Vegetable Cultivation Land In Rewarangga Selatan Viilage. Excessive use of inorganic fertilizers and intensive tillage can cause changes in chemical properties and soil fertility. This study aims to determine the chemical properties of the soil and the level of soil fertility on land that cultivates vegetables. The research was conducted in Rewarangga Selatan Village, Ende Regency. This research was conducted using a survey method, by taking soil samples by composite methods on spinach, mustard and kale vegetables. The variables observed were soil $\mathrm{pH}, \mathrm{C}-\mathrm{Organic}, \mathrm{P} 2 \mathrm{O} 5, \mathrm{~K} 2 \mathrm{O}, \mathrm{CEC}$, and $\mathrm{KB}$. These variables were analyzed for soil chemical properties and then matched using soil chemical criteria and soil fertility from the Bogor Soil Research Center. The results showed that the soil chemical criteria were soil $\mathrm{pH}$ in the acidic to very acidic category $(4.0-5.0)$, moderate C-Organic $(2.03 \%-2.37 \%)$, very high P2O5 (39.53 ppm - 48.90 ppm), very high K2O (1.01 me/100gr - 1.24 me/100gr), very high CEC (40.11 me/100gr - $40.33 \mathrm{me} / 100 \mathrm{gr})$, and very high KB $(82,11 \%-86.76 \%)$. While the criteria for soil fertility in the cultivation of vegetables are moderate.
\end{abstract}

Key Words: Chemical Properties, Fertility Criteria, Soil.

\section{PENDAHULUAN}

Tanah adalah lapisan permukaan bumi yang secara fisik berfungsi sebagai tempat tumbuh dan berkembangnya perakaran, penopang tegak tubuh tanaman dan menyuplai kebutuhan air dan udara.Secara kimiawi, tanah berfungsi sebagai tempat dan penyuplai hara atau nutrisi bagi tanaman, tempat tumbuh dan produksi tanaman (Arifin, 2011). Karena itu tanah merupakan komponen penting dalam penggunaan lahan.

Penggunaan lahan untuk pengembangan suatu komoditas sebaiknya didasarkan pada sifat tanah dan karakteristik lahan tanpa mengganggu keseimbangan ekologi. Produktivitas tanaman merupakan sinergi dari kemampuan suatu varietas dengan pengelolaan penggunaan lahan yang tepat. 
Oleh karena itu, pembudidayaan tanaman sangat dipengaruhi oleh kondisi lahan untuk mendukung hasil produksinya (Singh, 2012).

Para petani di desa Rewarangga Selatan mempunyai lahan pertanian yang cukup luas di dalam Kota Ende.Dalam kegiatan pertanian, untuk pembudidayaan tanaman sayur-sayuran petani Rewarangga Selatanmemiliki pasokan air yang melimpah. Dengan kapasitas air yang melimpah ini, petani Rewarangga Selatan manfaatkan lahan untuk bercocok tanam khususnyatanaman sayur-sayuran seperti kangkung, bayam dan sawi secara intensif sepanjang tahun.

Dalam usaha pertanian, petani Rewarangga Selatan tidak terlepas dari penggunaan pupuk anorganik untuk mempercepat pertumbuhan tanaman.Jenis pupuk yang sering digunakan petani yaitu pupuk Urea dan pupuk NPK Pelangi.Penggunaan pupuk anorganik secara terus-menerus menyebabkan tanah menjadi keras, serta kesuburan dan produktivitasnya menurun (Ikhsani et al., 2018). Penelitian (Walida et al., 2020), menjelaskan bahwa pupuk anorganik dapat menimbukan ketergantungan dan dapat menyebabkan tanah menjadi rusak dan berkurang tingakat kesuburannya.

(Suarjana et al., 2016) mengungkapkan bahwa, salah satu faktor yang menyebabkan menurunya hasil pertanian adalah kurang suburnya tanah. Tanah yang kurang subur, menyebabkan pasokan unsur hara bagi tanaman berkurang. Kesuburan tanah memegang peran penting dalam meningkatkan produksi dan produktifitas tanaman. Salah satu faktor penentunya adalah keberadaan unsur hara di dalam tanah tersebut. Unsur hara merupakan sifat kimia tanah yang sangat terkait dengan peningkatan produksi tanaman.

Beberapa sifat kimia tanah adalah COrganik tanah, Nitrogen, Kalium, Kapasitas Tukar Kation (KTK), Kejenuhan Basa (KB) dan pH (Tufaila \& Alam, 2014). Sifat-sifat kimia tanah tersebut merupakan penentu tingkat kesuburan tanah serta sangat terpengaruh dengan semakin intensifnya pengolahan Lahan serta penggunaan pupuk anorganik(Roidah, 2013).Berdasarkan pernyataan-pernyataan di atas maka perlu dilakukan penelitian untuk dapat mengetahui sifat kimia tanah dan tingkat kesuburan tanah pada lahan pertanian di Kelurahan Rewarangga Selatan yang dibudidayakan sayur-sayuran.

\section{BAHAN DAN METODE}

\section{Tempat dan Waktu Penelitian}

Kegiatan penelitian dilakukan pada area tanaman sayur-sayuran di Kelurahan Rewarangga Selatan, Kecamatan Ende Timur, Kabupaten Ende. Penelitian dilaksanakan dari bulan juli sampai bulan Oktober 2020. 


\section{Alat dan Bahan}

Alat yang digunakan adalah alat tulis, ring sampel, kertas label, plastik, linggis, cangkul, bor tanah, GPS, kamera digital, dan karet gelang. Bahan yang digunakan adalah sampel tanah terganggu yang diambil dari masing- masing lahan.

\section{Pelaksanaan Penelitian}

Pemilihan lokasi penelitian ditentukan dengan metode purposive sampling. Ketentuan dalam penentuan lokasi ini adalah lahan pertanian yang membudidayakan tanaman sayur-sayuran seperti sayur kangkung, bayam, dan sawi. Tanaman ini yang banyak dibudidayakan secara terus menerus dengan penggunaan pupuk anorganik secara rutin, tanpa melakukan masa bera pada lahan tersebut.

Teknik pengambilan sampel tanah menggunakan sampel tanah terganggu. Teknik pengambilan tanah ini dengan menggunakan kantong plastik dan diambil lima titik sampel pada setiap lahan. Setiap titik yang sudah ditentukan digali tanahnya dengan kedalaman $20 \mathrm{~cm}$. Selanjutnya sampel tanah tersebut pada setiap lahan yang sama dicampur atau dikomposit.

\section{Variabel Pengamatan}

Variabel yang diamati yaitu $\mathrm{pH}$ Tanah, C-Organik, P-Tersedia, K-Tersedia, Kapasitas Tukar Kation (KTK), dan Kejenuhan Basa (KB). pH tanah dianalisis dengan metode $\mathrm{pH}$ meter. C-Organik ditetapkan dengan menggunakan destruksi basah dan menggunakan kalium bichromat menurut metode Walkley and Black.Fosfat total $(\mathrm{mg} / 100 \mathrm{~g})$ ditetapkan dengan menggunakan ekstraksi HCL $25 \%$, sedangkan fosfat tersedia (ppm) ditetpakan dengan menggunakan ekstraksi Bray.Kalium total ditetapkan dengan menggunakan ekstraksi $25 \%$ HCL. KTK Ditetapkan dengan menjenuhkan menggunakan ammonium asetat $1 \mathrm{~N} \mathrm{Ph} \mathrm{7,0}$ (standard). KB dihitung berdasarkan jumlah basa-basa di bagi KTK dikalikan 100.

\section{Analisis Data}

Sampel tanah yang telah diambil dari lokasi penelitian dianalisis sifat kimia tanah di laboratorium. Setelah tanah dianalisis sifat kimianya, lalu dilakukan matching menggunakan Pusat Penelitian Tanah Bogor untuk menentukan criteria kimia tanah dan kesuburan tanah.

\section{HASIL DAN PEMBAHASAN}

Sifat kimia yang terdapat di lahan pembudidayaan tanaman sayur-sayuran di Kelurahan Rewarangga Selatan yang dapat diamati yaitu $\mathrm{pH}$ Tanah, C-Organik, PTersedia, K-Tersedia, Kapasitas Tukar Kation (KTK), dan Kejenuhan Basa (KB).Hasil analisis sifat kimia tanah menunjukan identifikasi kesuburan tanah dari lahan pembudidayaan tanaman sayursayuran di Kelurahan Rewarangga Selatan.

\section{Kriteria Kimia Tanah}


Banggo: Identifikasi tingkat kesuburan tanah dan sifat kimia tanah

Analisis kimia tanah dari kangkung telah dilakukan. Hasil analisis pembudidayaan tanaman bayam,sawi dan dapat dilihat pada Tabel 1.

Tabel 1. Kriteria Kimia Tanah Tanaman Sayur-sayuran Di Kelurahan Rewarangga Selatan

\begin{tabular}{|c|c|c|c|c|c|c|}
\hline \multirow{2}{*}{$\begin{array}{c}\text { Variabel } \\
\text { Kimia }\end{array}$} & \multicolumn{3}{|c|}{ Hasil Analisis } & \multicolumn{3}{|c|}{ Kategori } \\
\hline & S1 & S2 & S3 & S1 & S2 & S3 \\
\hline $\mathrm{pH}$ tanah & 4,0 & 5,0 & 5,0 & $\begin{array}{l}\text { Sangat } \\
\text { Masam }\end{array}$ & Masam & Masam \\
\hline C-Organik & $2,37 \%$ & $2,03 \%$ & $2,11 \%$ & Sedang & Sedang & Sedang \\
\hline P-Tersedia & $\begin{array}{l}48,90 \\
\text { ppm }\end{array}$ & $\begin{array}{l}40,21 \\
\text { ppm }\end{array}$ & $\begin{array}{l}39,53 \\
\mathrm{ppm}\end{array}$ & Tinggi & Tinggi & Tinggi \\
\hline K-Tersedia & $\begin{array}{l}1,24 \\
\mathrm{me} / 100 \mathrm{~g}\end{array}$ & $\begin{array}{l}1,01 \\
\mathrm{me} / 100 \mathrm{~g}\end{array}$ & $\begin{array}{l}1,02 \\
\mathrm{me} / 100 \mathrm{~g}\end{array}$ & $\begin{array}{l}\text { Sangat } \\
\text { Rendah }\end{array}$ & $\begin{array}{l}\text { Sangat } \\
\text { Rendah }\end{array}$ & $\begin{array}{l}\text { Sangat } \\
\text { Rendah }\end{array}$ \\
\hline KTK & $\begin{array}{l}40,33 \\
\mathrm{me} / 100 \mathrm{~g}\end{array}$ & $\begin{array}{l}40,33 \\
\mathrm{me} / 100 \mathrm{~g}\end{array}$ & $\begin{array}{l}40,11 \\
\mathrm{me} / 100 \mathrm{~g}\end{array}$ & $\begin{array}{l}\text { Sangat } \\
\text { Tinggi }\end{array}$ & $\begin{array}{l}\text { Sangat } \\
\text { Tinggi }\end{array}$ & $\begin{array}{l}\text { Sangat } \\
\text { Tinggi }\end{array}$ \\
\hline KB & $82,11 \%$ & $85,90 \%$ & $86,76 \%$ & $\begin{array}{l}\text { Sangat } \\
\text { Tinggi }\end{array}$ & $\begin{array}{l}\text { Sangat } \\
\text { Tinggi }\end{array}$ & $\begin{array}{l}\text { Sangat } \\
\text { Tinggi }\end{array}$ \\
\hline
\end{tabular}

Keterangan :

S1 : Sampel tanah sayur Bayam

S2 : Sampel tanah sayur Sawi

S3 : Sampel tanahsayur Kangkung

\section{pH Tanah}

Berdasarkan hasil analisis laboratorium kimia tanah diketahui bahwa $\mathrm{pH}$ tanah pada lahan pembudidayaan tanaman sayursayuran di Kelurahan Rewarangga Selatan berada pada kisaran $\mathrm{pH} 4,0-5,0$ yang tergolong dalam sangat masam sampai masam.Reaksi tanah (nilai $\mathrm{pH}$ ) dapat dipengaruhi oleh penggunaan pupuk anorganik dengan dosis yang berlebihan untuk tanaman (Dharmayanti et al., 2013; Padmanabha et al., 2014).

Menurut (Nurmasyitah et al., 2013), $\mathrm{pH}$ tanah yang rendah akan menyebabkan ketersediaan hara menurun dan perombakan bahan organik terhambat sehingga menurunnya tingkat kesuburan tanah. $\mathrm{pH}$ tanah merupakan reaksi tanah yang menunjukkan kemasaman atau alkalitas tanah. $\mathrm{pH}$ tanah berperan penting dalam menentukan mudah tidaknya unsurunsur hara yang diserap oleh tanaman.

Hanafiah (2012) mengungkapkan bahwa mikroorganisme tanah dan jamur dapat berkembang dengan baik pada $\mathrm{pH}$ diatas 5,5 jika kurang akan terhambat aktivitasnya. pH tanah yang rendah akan menyebabkan tanaman tidak dapat memanfaatkan unsur hara yang dibutuhkan. $\mathrm{pH}$ yang rendah juga menyebabkan tersedianya unsur beracun seperti aluminium yang selalu meracuni tanaman 
dan juga mengikat fosfor sehingga tidak bias diserap oleh tanaman.

\section{C-Organik}

Hasil analisis menunjukan bahwa kandungan C-Organik pada lahan pembudidayaan tanaman sayur-sayuran di Kelurahan Rewarangga Selatan tergolong sedangdengan nilai $\left(\mathrm{S}_{1} 2,37 \%\right),\left(\mathrm{S}_{2} 2,03 \%\right)$ dan $\left(\mathrm{S}_{3} 2,11 \%\right)$. Nilai C-Organik pada tanah penelitian tergolong sedang disebabkan karena penggunaan pupuk anorganik yang berlebihan tanpa diimbangi pupuk organik(Pane 2016). Hal ini didukung oleh (Widodo et al., 2016), bahwa lahan yang diolah secara terus-menerus dan diikuti dengan pemberian pupuk kimia dalam jangka panjang akan menyebabkan penurunan kandungan bahan organik tanah, kualitas tanah, dan produksi tanaman.

\section{P-Tersedia}

Analisis $\mathrm{P}$ tersedia menunjukkan bahwa fosfor tanahnya tergolong tinggi. Hal ini dapat terjadi karena para petani sering menggunakan pupuk anorganik dengan dosis berlebihan (Mawardiana et al., 2013). Penelitian lainnya yang mendukung hal ini adalah hasil peneltian dari (Dharmayanti et al., 2013) yang menyebutkan bahwa pemberian pupuk NPK memberikan pengaruh yang signifikan terhadap sifat fisik dan kimia tanah. Hal ini karena residu $\mathrm{P}$ yang diendapkan secara terus menerus melalui kegiatan pemupukan.

\section{K-Tersedia}

Hasil analisis Laboratorium yang dilakukan terhadap unsur $\mathrm{K}$ menunjukkan kandungan yang sangat rendah $(1,24$ $\mathrm{me} / 100 \mathrm{~g}-1,02 \mathrm{me} / 100 \mathrm{~g})$. Hal ini dapat terjadi karena unsur $\mathrm{K}$ merupakan unsur yang sangat mobile di dalam tanah. Karenanya unsur ini dapat hilang karena berbagai faktor diantaranya pencuci. Menurut (Soekamto, 2015), menjelaskan bahwa ion $\mathrm{K}$ tergolong unsur yang mudah bergerak sehingga mudah sekali hilang dari tanah melalui pencucian.Penyebab rendahnya kalium dalam tanah dipengaruhi oleh bahan induk juga $\mathrm{pH}$ tanah (Padmanabha et al., 2014; Tufaila \& Alam, 2014)

\section{Kapasitas Tukar Kation (KTK)}

Berdasarkan hasil analisis tanah nilai KTK tanah pada lokasi penelitian berkisar antara40,33 me/100g-40,11 me/100g yang tinggi. KTK dipengaruhi oleh kandungan tipe liat dan kandungan bahan organik. KTK tanah menggambarkan kation-kation tanah seperti kation $\mathrm{Ca}, \mathrm{Mg}$, dan $\mathrm{Na}$ yang dapat ditukar dan diserap olehperakaran tanaman(Molle et al., 2021; Soekamto, 2015). Peningkatan KTK tanah disebabkan oleh bahan organik yang mengalami dekomposisi menghasilkan senyawasenyawa organik sehingga meningkatkan KTK tanah.(Hardjowigeno, 2010), menyampaikan KTK sangat dipengaruhi 
Banggo: Identifikasi tingkat kesuburan tanah dan sifat kimia tanah

oleh fraksi liat dan kandungan organik tanah.Bahan organik memiliki gugus fungsional yang dapat menyumbangkan muatan negatif pada tanah. Muatan negatif dari bahan organik mampu mempertukarkan kation sehingga mampu meningkatkan kapasitas tukar kation tanah(RR Darlita et al., 2017).

\section{Kejenuhan Basa (KB)}

Hasil analisis laboratorium menunjukan bahwa Kejenuhan Basa (KB) tanah pada lahan pembudidayaan tanaman sayur-sayuran di Kelurahan Rewarangga Selatan berkisaran antara $82,11 \%, 85,90 \%$ dan $86,76 \%$ (tergolong kriteria tinggi). Persentase nilai KB yang tinggi dikarenakan pemberian pupuk anorganik (kimia) sehingga dapat meningkatkan persentase nilai $\mathrm{KB}$ di dalam tanah (Mawardiana et al., 2013).Hal ini didukung oleh (Roidah, 2013), yang menyatakan bahwa penggunaan pupuk anorganik dapat berdampak pada peningkatan KB. Kejenuhan basa menunjukan perbandingan antara jumlah kation-kation basa dengan jumlah kation (kation basa dan kation asam) yang dapat dalam kompleks serapan tanah.

\section{Kriteria Kesuburan Tanah}

Kesuburan tanah merupakan suatu keadaan tanah dimana tata air, udara dan unsur hara dalam keadaan cukup seimbang dan dan tersedia sesuai kebutuhan tanaman, baik sifat fisik, biologi dan kimia tanah. Tabel kesuburan tanah dapat dilihat pada Tabel 2 dibawah ini:

\section{Tabel 2 Kesuburan Tanah}

\begin{tabular}{ccccccc}
\hline $\begin{array}{c}\text { Sam } \\
\text { pel }\end{array}$ & $\begin{array}{c}\text { KTK } \\
(\mathbf{M e} / \mathbf{1 0} \\
\mathbf{0 g})\end{array}$ & $\begin{array}{c}\text { KB } \\
\mathbf{\%}\end{array}$ & $\begin{array}{c}\text { C- } \\
\text { Organik } \\
\mathbf{\%}\end{array}$ & $\begin{array}{c}\mathbf{P}_{2} \mathbf{O}_{5} \\
(\mathbf{M e} / \mathbf{1 0 0 g})\end{array}$ & $\begin{array}{c}\mathbf{K}_{2} \mathbf{O} \\
(\mathbf{M e} / \mathbf{1 0 0 g})\end{array}$ & $\begin{array}{c}\text { Status } \\
\text { Kesuburan } \\
\text { Tanah }\end{array}$ \\
\hline S1 & $40,33 \mathrm{~T}$ & $82,11 \mathrm{~T}$ & $2,37 \mathrm{~S}$ & $48,90 \mathrm{~T}$ & $1,24 \mathrm{R}$ & Sedang \\
S2 & $40,33 \mathrm{~T}$ & $85,90 \mathrm{~T}$ & $2,03 \mathrm{~S}$ & $40,21 \mathrm{~T}$ & $1,01 \mathrm{R}$ & Sedang \\
S3 & $40,11 \mathrm{~T}$ & $86,76 \mathrm{~T}$ & $2,11 \mathrm{~S}$ & $39,52 \mathrm{~T}$ & $1,02 \mathrm{R}$ & Sedang \\
\hline
\end{tabular}

Ketrangan :

$\mathrm{T}$ : Tinggi

$\mathrm{R}$ :Rendah

$\mathrm{S}$ : Sedang

Hasil evaluasi status kesuburan tanah menunjukan kriteria kesuburan tanah Sedang. Hal ini dikarenakan adanya faktor penghambat yaitu C-Organik tanah sedang dan Kalium rendah.Keadaan ini menandakan pemupukan kalium sangat diperlukan agar produksi dan kualitas tanah tetap terjaga.Menurut(Kusuma, 2013)pemberian bahan organik pada tanah dapat meningkatkan kandungan $\mathrm{K}$ untuk 
tanaman karena adanya pembentukan kompleks kalium. Sehingga perlu penambahan bahan organik ke dalam tanahseperti pemberian pupukorganik.

Hasil penelitian Rohmah dan Suntari (2019)menyebutkan bahwa penambahan bahan organik sangat membantu dalam memperbaiki tanah yang kurang subur.Hal ini dapat terjadi karena penggunaan pupuk organik meningkatkan ketersediaan unsur hara di dalam tanah.

\section{SIMPULAN}

Kriteria kimia tanah yang ada pada lahan pembudidayaan tanaman sayursayuran di Kelurahan Rewarangga Selatan yaitu $\mathrm{pH}$ tanah termasuk kategori masam sampai sangat masam, C-Organik tergolong sedang, $\mathrm{P}_{2} \mathrm{O}_{5}$ tergolong tinggi, $\mathrm{K}_{2} \mathrm{O}$ tergolong rendah, KTK tergolong tinggi, dan KB tergolong tinggi.Kriteria kesuburan tanah di lahan pembudidayaan tanaman sayur-sayuran yaitu tergolong sedang dengan faktor pembatas Kalium.

\section{UCAPAN TERIMAKASIH}

Penyelesaian tulisan ini karena campur tangan berbagai pihak. Karena itu penulis mengucapkan terimakasih kepada segenap pihak yang telah berpartisipasi dalam penyelesaian tulisan ini.

\section{DAFTAR PUSTAKA}

Arifin. (2011). Ilmu Tanah. Akademik Ressindo.

Dharmayanti, N., Supadma, A., \&
Arthagama, I. (2013). Pengaruh Pemberian Biourine Dan Dosis Pupuk Anorganik $(\mathrm{N}, \mathrm{P}, \mathrm{K}) \quad$ Terhadap Beberapa Sifat Kimia Tanah Pegok Dan Hasil Tanaman Bayam (Amaranthus Sp.). E-Jurnal Agroekoteknologi Tropika (Journal of Tropical Agroecotechnology), 2(3), 165-174.

https://ojs.unud.ac.id/index.php/JAT/a rticle/view/6077

Hanafiah, K. . (2012). Dasar-Dasar Ilmu Tanah. PT Raja Grafindo Persada.

Hardjowigeno. (2010). Ilmu Tanah. Akademika Pressindo.

Ikhsani, D., Hindersah, R., \& Herdiyantoro, D. (2018). Pertumbuhan Tanaman Kacang Tanah (Arachis hypogea L. Merril) Setelah Aplikasi Azotobacter chroococcum Dan Pupuk NPK. Agrologia, $\quad 7(1), \quad 1-8$. https://doi.org/10.30598/a.v7i1.351

Kusuma, M. E. (2013). Pengaruh Pemberian Pupuk Bokashi Terhadap Pertumbuhan Vegetatif Rumput Gajah (Pennisetum Purpureum). Ilmu Hewani Tropika, 2(2), 40-45. https://doi.org/10.31602/zmip.v42i2.7 75

Mawardiana, Sufardi, \& Edi, H. (2013). Pengaruh Residu Biochar Dan Pemupukan Npk Terhadap Sifat Kimia Tanah Dan Pertumbuhan Serta Hasil Tanaman Padi Musim Tanam Ketiga. 
Banggo: Identifikasi tingkat kesuburan tanah dan sifat kimia tanah

Jurnal Manajemen Sumber Daya

Lahan, 2(3), 255-260. http://erepository.unsyiah.ac.id/MSDL/article /view/2198

Molle, E. S., Wijaya, A. S., \& Sutrisno, A. J. (2021). Penilaian Status Kesuburan Tanah Desa Tijayan Kecamatan Manisrenggo Kabupaten Klaten. Agrotechnology Research Journal, $5(2)$, $48-54$.

https://doi.org/10.20961/agrotechresj.v $5 \mathrm{i} 2.54230$

Nurmasyitah, N., Syafruddin, S., \& Sayuthi, M. (2013). Pengaruh Jenis Tanah Dan Dosis Fungi Mikoriza Arbuskular Pada Tanaman Kedelai Terhadap Sifat Kimia Tanah. Jurnal Agrista, 17(3), 103-110. http://www.jurnal.unsyiah.ac.id/agrista /article/view/1495

Padmanabha, I. G., Arthagama, I. D. M., \& Dibia, I. N. (2014). Pengaruh Dosis Pupuk Organik dan Anorganik terhadap Hasil Padi (Oryza Sativa L.) dan Sifat Kimia Tanah pada Inceptidol Kerambitan Tabanan. E-Jurnal Agroekoteknologi Tropika, 3(1), 4150.

https://simdos.unud.ac.id/uploads/file_ penelitian_1_dir/01070a399b28f61188 423f4ae6982bf1.pdf

Rohmah, A., \& Suntari, R. (2019). Efek Pupuk Bokashi Terhadap Ketersediaan Unsur Basa (K, Na, Ca, dan Mg) Pada
Inceptisol Karangploso Malang. Jurnal Tanah Dan Sumberdaya Lahan, $\quad$ 6(2), 1273-1279. https://doi.org/10.21776/ub.jts1.2019.0 06.2 .8

Roidah, I. S. (2013). Manfaat Penggunaan Pupuk Organik Untuk Kesuburan Tanah. Universitas Tulungagung Bonorowo, 1(1), 30-42. https://doi.org/https://doi.org/10.36563 /bonorowo.v1i1.5

RR Darlita, R. D., Joy, B., \& Sudirja, R. (2017). Analisis Beberapa Sifat Kimia Tanah Terhadap Peningkatan Produksi Kelapa Sawit pada Tanah Pasir di Perkebunan Kelapa Sawit Selangkun. Agrikultura, 28(1), 15-20. https://doi.org/10.24198/agrikultura.v2 8 i1.12294

Singh, S. (2012). Land Suitability Evaluation and Landuse Planning Using Remote Sensing Data and Geographic Information System Techniques. Online) An Online International Journal Available At, 2(1), 1-6. http://www.cibtech.org/jgee.htm

Soekamto, M. H. (2015). Kajian Status Kesuburan Tanah Di Lahan Kakao Kampung Klain Distrik Mayamuk Kabupaten Sorong. Jurnal Agroforestri, 10(3), 201-208. https://jurnalee.files.wordpress.com/20 16/06/kajian-status-kesuburan-tanah- 
di-lahan-kakao-kampung-klain-distrikmayamuk-kabupaten-sorong.pdf

Suarjana, I., Supadma, A., \& Arthagama, I. (2016). Kajian Status Kesuburan Tanah Sawah Untuk Menentukan Anjuran Pemupukan Berimbang Spesifik Lokasi Tanaman Padi Di Kecamatan Manggis. E-Jurnal Agroekoteknologi Tropika (Journal of Tropical Agroecotechnology), 4(4), 314-323.

https://ojs.unud.ac.id/index.php/JAT/a rticle/view/18019

Tufaila, M., \& Alam, S. (2014). Karakteristik Tanah dan Evaluasi Lahan untuk Pengembangan Tanaman Padi Sawah di Kecamatan Oheo Kabupaten Konawe Utara. Jurnal AGRIPLUS, 24(2), 184-194. https://www.researchgate.net/profile/S yamsu-Alam-

4/publication/335854519_Karakteristi

k_Tanah_dan_Evaluasi_Lahan_untuk _Pengembangan_Tanaman_Padi_Saw ah_di_Kecamatan_Oheo_Kabupaten_
Konawe_Utara/links/5d803ecea6fdcc6 6b001b802/Karakteristik-Tanah-danEvaluasiWalida, H., Harahap, F. S., Dalimunthe, B. A., Hasibuan, R., Nasution, A. P., \& Sidabuke, S. H. (2020). Pengaruh Pemberian Pupuk Urea Dan Pupuk Kandang Kambing Terhadap Beberapa Sifat Kimia Tanah Dan Hasil Tanaman Sawi Hijau. Jurnal Tanah Dan Sumberdaya Lahan, 7(2), 283-289.

https://doi.org/10.21776/ub.jts1.2020.0 07.2.12

Widodo, E. A., Niswati, A., Yusnaini, S., \& Buchori, H. (2016). Pengaruh Pengolahan Tanah Dan Pemberian Mulsa Bagas Terhadap Biomassa Karbon Mikroorganisme Tanah (CMik) Pada Lahan Pertanaman Tebu Pt Gmp Tahun Ketiga. Jurnal Agrotek Tropika, 4(3), 228-232. https://doi.org/http://dx.doi.org/10.239 60/jat.v4i3.1857 